\title{
PERANCANGAN SISTEM STANDARISASI DESA WISATA KABUPATEN BANTUL DENGAN MODEL SISTEM PENGUKURAN KINERJA BALANCED SCORECARD GUNA PENGUATAN INDUSTRI PARIWISATA DAERAH
}

\author{
Yasrin Zabidi ${ }^{1}$, Suhardiwarno ${ }^{2}$ \\ ${ }^{1}$ Prodi Teknik Industri, ${ }^{2}$ Prodi Teknik Penerbangan \\ Sekolah Tinggi Teknologi Adisutjipto \\ Jl. Janti Blok R Lanud Adisutjipto Yogyakarta \\ 1yazma_2000@yahoo.com, ${ }^{2}$ hardistta@gmail.com
}

\begin{abstract}
Bantul regency until now has approximately 36 villages wisata. Standarisasi tourist village needs to be done, which is the standard tourist village which is categorized as an embryo, develops, and advanced. These standards can be used by Disbudpar to determine work programs such as mentoring programs, counseling, training for rural tourism in the category or the developing embryo. One standardized assessment instrument is the assessment of performance against a tourist village.

Therefore, in this study, researchers are trying to design a system of standardization of the tourist village of Bantul model performance measurement system balanced scorecard that includes the identification of performance criteria, strategic objectives, determining indicators of performance, the determination method/means of performance measurement precise, systematic and easy to use, as well as the design of performance reporting.

The design activity in this study is divided into four phases, namely: the initial phase of the study and formulation of the problem, the design phase, the phase of analysis and conclusion phase. Early research phase and the formulation of the problem include the formulation of the problem and determine the research objectives. Design phase includes the design process performance measurement system with Balanced Scorecard method which includes the establishment of strategic objectives, the establishment of performance indicators (key performance indicators / KPIs), target setting and action plans, draft worksheet performance measurement methods Omax and draft reporting of performance-based website. Phase analysis includes analysis of balanced scorecard performance measurement system that includes analysis perspective, the analysis of strategic objectives, KPI analysis and analysis of the strategy map. Phase conclusions include conclusions from the findings and suggestions.

From the research performance based on four perspectives of the balanced scorecard, namely financial, customer, internal business processes, learning and growth. Strategic objectives that form there are 10 and there are 24 KPI KPI formed. Besides of this study the formation worksheet Omax performance measurement method, so that can know the value of each performance indicator of performance and total performance in a particular period.
\end{abstract}

Keywords: Tourism Village, Performance, Standards, Performance Measurement, Balanced Scorecard 


\begin{abstract}
Abstrak
Kabupaten Bantul sampai saat ini memiliki kurang lebih 36 desa wisata. Standarisasi desa wisata perlu dilakukan, yaitu standar desa wisata mana yang masuk kategori embrio, berkembang, dan maju. Standarisasi ini dapat digunakan oleh Disbudpar untuk menentukan program kerja seperti program pendampingan, penyuluhan, pelatihan bagi desa wisata yang masuk dalam kategori embrio atau berkembang. Salah satu instrumen penilaian standarisasi adalah penilaian kinerja terhadap desa wisata.
\end{abstract}

Oleh karena itu pada penelitian ini, peneliti mencoba untuk merancang sistem standarisasi desa wisata Bantul dengan model sistem pengukuran kinerja balanced scorecard yang meliputi identifikasi kriteria kinerja, tujuan strategik, penentuan indikator kinerja, penentuan metode/cara pengukuran kinerja yang tepat, sistematis dan mudah digunakan, serta desain pelaporan kinerja.

Rancangan kegiatan dalam penelitian ini terbagi atas empat fase, yaitu: fase penelitian awal dan perumusan masalah, fase perancangan, fase analisis dan fase kesimpulan. Fase penelitian awal dan perumusan masalah meliputi, perumusan masalah dan penentuan tujuan penelitian. Fase perancangan meliputi proses perancangan sistem pengukuran kinerja dengan metode Balanced Scorecard yang meliputi penetapan tujuan strategik, penetapan indikator-indikator kinerja (key performance indicator/KPI), penetapan target dan rencana aksi, rancangan lembar kerja pengukuran kinerja dengan metode Omax dan rancangan pelaporan kinerja berbasis website. Fase analisis meliputi analisis sistem pengukuran kinerja balanced scorecard yang meliputi analisis perspektif, analisis tujuan-tujuan strategik, analisis KPI dan analisis peta strategi. Fase kesimpulan meliputi kesimpulan dari hasil penelitian serta saran-saran.

Dari hasil penelitian diperoleh 4 perspektif kinerja berdasarkan balanced scorecard, yaitu finansial, pelanggan, proses bisnis internal, belajar dan tumbuh. Tujuan-tujuan strategis yang terbentuk ada 10 dan KPI yang terbentuk ada 24 KPI. Selain itu dari penelitian ini terbentuknya lembar kerja pengukuran kinerja dengan metode Omax, sehingga dapat diketahui nilai kinerja tiap indikator kinerja dan total kinerja dalam periode tertentu.

Kata kunci: Desa Wisata, Kinerja, Standarisasi, Pengukuran Kinerja, Balanced Scorecard

\title{
1. Pendahuluan
}

\subsection{Latar Belakang Masalah}

Kabupaten Bantul sampai saat ini memiliki sekitar 36 desa wisata. Untuk membuat desa wisata, setidaknya harus memiliki Anggaran Dasar Rumah Tinggi (AD/ART), pengukuhan dari lurah atau surat keputusan (SK), kemudian didaftarkan ke Dinas Budaya dan Pariwisata (Disbudpar). Disbudpar akan melakukan verifikasi apakah desa wisata tersebut layak atau belum. Selanjutnya Disbudpar mengeluarkan surat keputusan (SK) desa wisata. SK ini dapat dimanfaatkan oleh desa wisata untuk memperoleh dana keistimewaan (danais). Standarisasi desa wisata perlu dilakukan, yaitu standar desa wisata mana yang masuk kategori embrio, berkembang, dan maju. Standarisasi ini digunakan oleh Disbudpar untuk menentukan program kerja seperti program pendampingan, penyuluhan, pelatihan bagi desa wisata yang masuk dalam kategori embrio atau berkembang. Salah satu instrumen penilaian standarisasi adalah penilaian kinerja terhadap desa wisata. Faktor yang penting dalam mempengaruhi proses kemajuan dan kemunduran suatu organisasi dalam hal ini desa wisata adalah faktor kinerja, artinya meningkatkan kinerja berarti meningkatkan kesejahteraan dan kualitas desa wisata. Masalah kinerja bukan hanya penting bagi perusahaan, tetapi juga penting bagi suatu organisasi/kelompok seperti desa wisata. Kelancaran proses kegiatan dan kemajuan organisasi tidak terlepas dari peran kinerja itu sendiri. Tanpa kinerja maka matilah proses kegiatan 
tersebut. Desa wisata juga merupakan salah satu bentuk kegiatan di bidang pariwisata yang berada pada suatu wilayah/daerah serta memiliki peran sangat penting bagi berlangsungnya perekonomian daerah, kesejahteran masyarakat.

Untuk melakukan penilaian kinerja terlebih dahulu harus dibentuk sistem pengukuran kinerja. Sistem pengukuran kinerja selain dapat digunakan oleh Disbudpar Bantul sebagai instrumen penilaian standarisasi desa wisata juga dapat digunakan oleh pengelola desa wisata untuk memotret diri/mengevaluasi diri, apakah desa wisata yang dikelolanya berkinerja baik, sedang atau buruk.

Oleh karena itu pada penelitian ini, peneliti mencoba untuk merancang sistem standarisasi desa wisata Bantul dengan model sistem pengukuran kinerja (balanced scorecard) yang meliputi identifikasi kriteria kinerja, tujuan strategik, penentuan indikator kinerja, penentuan metode/cara pengukuran kinerja yang tepat, sistematis dan mudah digunakan, serta desain pelaporan kinerja.

\subsection{Perumusan Masalah}

1. Bagaimana merancang sistem standarisasi desa wisata di wilayah Kabupaten Bantul dengan model sistem pengukuran kinerja balanced scorecard?

2. Sejauh mana model sistem pengukuran kinerja balanced scorecard dapat dijadikan instrumen penilaian standarisasi desa wisata di Kabupaten Bantul dan instrumen evaluasi diri terhadap pengelolaan desa wisata?

\subsection{Manfaat Penelitian}

Terbentuknya Sistem Standarisasi Desa Wisata berbasis pengukuran kinerja untuk menentukan standar desa wisata mana yang masuk kategori embrio, berkembang, dan maju.

\section{Metodologi Penelitian}

Metode perancangan sistem standarisasi desa wisata menggunakan model sistem pengukuran kinerja Balanced Scorecard. Model ini dipilih karena mengakomodasi kriteria finansial dan non finansial yang sistematis karena memiliki langkah-langkah perancangan yang sistematis, selain itu Balanced Scorecard memiliki korelasi dan integrasi yang tinggi dengan strategi jangka pendek maupun jangka panjang karena dibangun dari visi, misi dan strategi organisasi. Analisis yang akan digunakan dalam penelitian ini adalah dengan analisis kualitatif dan analisis kuantitatif, tetapi dengan penekanan pada analisis kualitatif. Sedangkan analisis kuantitatif hanya sebagai pendukung untuk suatu kesimpulan yang diambil.

Langkah-langkah dalam penelitian ini terbagi atas empat fase, yaitu: fase penelitian awal dan perumusan masalah, fase perancangan, fase analisis dan fase kesimpulan. Fase penelitian awal dan perumusan masalah meliputi, profil desa wisata di Bantul, perumusan masalah dan penentuan tujuan penelitian. Fase perancangan meliputi proses perancangan sistem pengukuran kinerja dengan metode Balanced Scorecard yang meliputi penetapan arsitektur yang terdiri atas visi, misi dan strategi organisasi, penetapan tujuan strategik, penetapan indikator-indikator kinerja (key performance indicator), penetapan target dan rencana aksi, rancangan lembar kerja/software pengukuran kinerja dengan metode Objective Matrix (Omax). Fase analisis meliputi analisis sistem pengukuran kinerja balanced scorecard 
yang meliputi analisis perspektif, analisis tujuan-tujuan strategik, analisis KPI dan analisis peta strategi. Fase kesimpulan meliputi kesimpulan dari hasil penelitian serta saran-saran bagi desa wisata di Bantul dan kelanjutan penelitian ini.

\section{Hasil Penelitian}

\subsection{Tujuan-tujuan Strategis}

Tabel 1. Tujuan-Tujuan Strategis

\begin{tabular}{|c|c|c|}
\hline No & Perspektif & Tujuan-Tujuan Strategis \\
\hline 1 & Finansial & $\begin{array}{l}\text { 1. Meningkatkan jumlah pendapatan } \\
\text { 2. Meningkatkan ketertiban administrasi keuangan }\end{array}$ \\
\hline 2 & Pelanggan & $\begin{array}{l}\text { 1. Meningkatkan pertumbuhan wisatawan baik lokal maupun } \\
\text { mancanegara } \\
\text { 2. Meningkatkan kepuasan wisatawan }\end{array}$ \\
\hline 3 & $\begin{array}{l}\text { Proses Bisnis } \\
\text { Internal }\end{array}$ & $\begin{array}{l}\text { 1. Terwujudnya daya tarik wisata yang berdaya saing } \\
\text { 2. Meningkatkan sistem dan proses pengelolaan desa wisata yang } \\
\text { lebih baik } \\
\text { 3. Meningkatkan ketersediaan sarana prasarana desa wisata yang } \\
\text { memadai }\end{array}$ \\
\hline 4 & $\begin{array}{l}\text { Belajar dan } \\
\text { Pertumbuhan }\end{array}$ & $\begin{array}{l}\text { 1. Terciptanya iklim organisasi pengelola desa wisata yang baik } \\
\text { 2. Meningkatkan keterampilan para anggota pengelola desa wisata } \\
\text { 3. Terwujudnya masyarakat yang paham/melek terhadap desa wisata. }\end{array}$ \\
\hline
\end{tabular}

\subsection{Indikator Kinerja}

Tabel 2. Indikator Kinerja

\begin{tabular}{|c|c|}
\hline Key Performance Indicators & Formula \\
\hline \multicolumn{2}{|l|}{ Perspektif Finansial } \\
\hline 1. Jumlah pendapatan & $\begin{array}{l}\text { Jumlah pendapatan yang diperoleh dari tiap-tiap } \\
\text { jenis pendapatan selama } 1 \text { tahun }\end{array}$ \\
\hline \multirow[t]{2}{*}{ 2. $\quad$ Persentase pertumbuhan pendapatan } & (Pendapatan tahun ini) - (Pendapatan tahun lalu) ${ }^{2} 100 \%$ \\
\hline & Pendapatan tahun lalu $\times 100 \%$ \\
\hline 3. Ketersediaan pelaporan keuangan & Skor ketersediaan : $1-4$ \\
\hline \multicolumn{2}{|l|}{ Perspektif Pelanggan } \\
\hline 1. Jumlah wisatawan & Jumlah wisatawan selama 1 tahun \\
\hline \multirow[t]{2}{*}{ 2. Persentase pertumbuhan wisatawan } & (Jml.wisatawan tahun ini) $-\left(\mathrm{Jml}\right.$. wisatawan tahun lalu) $\mathrm{y} 100^{\circ}$ \\
\hline & Jml. wisatawan tahun lalu \\
\hline 3. Jumlah wisatawan nusantara (wisnu) & Jumlah wisnu selama 1 tahun \\
\hline \multirow{2}{*}{$\begin{array}{l}\text { 4. Persentase pertumbuhan wisatawan } \\
\text { nusantara }\end{array}$} & (Jml.wisnu tahun ini $)-(\mathrm{Jml}$. wisnu tahun lalu $) \times 100 \%$ \\
\hline & Jml. wisnu tahun lalu $\times 100 \%$ \\
\hline $\begin{array}{l}\text { 5. Jumlah wisatawan mancanegara } \\
\text { (wisma) }\end{array}$ & Jumlah wisma selama 1 tahun \\
\hline \multirow{2}{*}{$\begin{array}{l}\text { 6. Persentase pertumbuhan wisatawan } \\
\text { mancanegara }\end{array}$} & (Jml.wisma tahun ini $)-(\mathrm{Jml}$. wisma tahun lalu $)$ \\
\hline & Jml. wisma tahun lalu \\
\hline 7. Tingkat kepuasaan wisatawan & Skor kepuasan $1-4$ (Survey kepuasan ) \\
\hline
\end{tabular}




\section{Perspektif Proses Bisnis Internal}

\begin{tabular}{lll}
\hline 1. & Persentase efektifitas promosi & Jml. wisatawan tahun ini \\
\cline { 3 - 3 }$\times 100 \%$ & Jml. wisatawan tahun lalu \\
\hline 2. & Ketersediaan promosi & Skor 1 - 4 \\
\hline 3. & Jumlah daya tarik wisata & Jumlah daya tarik wisata selama 1 tahun \\
\hline 4. & Ketersediaan paket wisata & Skor 1 - 4 \\
\hline 5. & Jumlah penghargaan yang diperoleh & Banyaknya penghargaan yang diperoleh \\
\hline 6. & Ketersediaan penginapan/homestay & Skor $1-4$ \\
\hline 7. & Ketersediaan rumah makan/restoran & Skor $1-4$ \\
\hline 8. & Ketersediaan fasilitas MCK & Skor $1-4$ \\
\hline 9. & Ketersediaan fasilitas parkir & Skor 1 - 4 \\
\hline 10. & Kemudahaan akses ke desa wisata & Skor $1-4$ \\
\hline
\end{tabular}

\section{Perspektif Belajar dan Pertumbuhan}

1. Tingkat kepuasan masyarakat terhadap Skor kepuasan $1-4$ (Survey kepuasan ) pengelola desa wisata

2. Tingkat kepuasan anggota pengelola Skor kepuasan $1-4$ (Survey kepuasan ) terhadap manajemen

3. Tingkat pemahaman masyarakat Skor $1-4$ terhadap desa wisata

4. Jumlah peserta pelatihan $\quad$ Banyaknya peserta pelatihan yang dikirim

\subsection{Lembar Kerja Pengukuran Kinerja}

Contoh pengukuran kinerja ini juga merupakan bentuk validasi dari sistem pengukuran kinerja yang terbentuk.

Tabel 3. Contoh Lembar Kerja Pengukuran Kinerja KPI 1 - KPI 9

\begin{tabular}{|c|c|c|c|c|c|c|c|c|c|c|c|}
\hline Indikator Kinerja (KPI) & KPI 1 & KPI 2 & KPI 3 & KPI 4 & KPI 5 & KPI 6 & KPI 7 & KPI 8 & KPI 9 & SCORE & KEIERAVGAY \\
\hline Pencapajan & 27,0000000 & $13 \%$ & 3.0 & 425.0 & $13 \%$ & 3000 & $14 \%$ & 185.0 & $15 \%$ & & \\
\hline Iarget & $37,300,0000$ & $19 \%$ & 4.0 & 562.5 & $19 \%$ & 3750 & $19 \%$ & 250.0 & $19 \%$ & 10 & Sangat Baili \\
\hline & $31,714,286$ & $13 \%$ & 3.4 & 492.9 & $15 \%$ & 3214 & $15 \%$ & 207.1 & $15 \%$ & 7 & \multirow{2}{*}{ Baili } \\
\hline & 29.785 .714 & $14 \%$ & 3.1 & 469.6 & 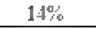 & 3036 & $14 \%$ & 192.9 & $14 \%$ & 6 & \\
\hline & $27,857,143$ & $13 \%$ & 2.9 & 416.4 & $13 \%$ & 285.7 & $13 \%$ & 178.6 & $13 \%$ & $\overline{3}$ & \multirow{3}{*}{ Sedang } \\
\hline & 25.928 .571 & $11 \%$ & 2.7 & 423.2 & $11 \%$ & 2679 & $11 \%$ & 164.3 & $11 \%$ & 4 & \\
\hline & 24.0000000 & $10 \%$ & 2.5 & $\$ 00.0$ & $10 \%$ & 2500 & $10 \%$ & 150.0 & $10 \%$ & 3 & \\
\hline & 20.0000000 & $8 \%$ & 2.3 & 386.7 & $8 \%$ & 233.3 & $8 \%$ & 143.3 & $8 \%$ & 2 & Buruk: \\
\hline Bobot & 0.041607 & 0.041667 & 0.041667 & 0.041667 & 0.041607 & 0.041567 & 0.041667 & 0.041667 & 0.041667 & & \\
\hline Nilai Kïnerija & 0.21 & 0.21 & 0.21 & 0.17 & 0.21 & 0.25 & 0.25 & 0.21 & 0.29 & & \\
\hline STATLS KI \ERJA & Sedang & Sedane & Sedane & Sedang & Sedane & Baili & Baili & Sedane & Baili & & \\
\hline
\end{tabular}


Tabel 4. Contoh Lembar Kerja Pengukuran Kinerja KPI 10 - KPI 18

\begin{tabular}{|c|c|c|c|c|c|c|c|c|c|c|c|}
\hline Indilator Kïnerja (KPI) & KPI 10 & KPI 11 & KPI 12 & KPI 13 & KPI 14 & KPI 15 & KPI 16 & KPI 17 & KPI 19 & SCORE & KEIERANGAY \\
\hline Pencapaian & 3.5 & $43 \%$ & 3.0 & 3.0 & 3.0 & 1.0 & 3 & 3.0 & 3.0 & & \\
\hline & 3.9 & $57 \%$ & 3.8 & 3.7 & 3.7 & 1.9 & 4 & 3.7 & 3.7 & 9 & \multirow{4}{*}{ Baili } \\
\hline & 3.7 & $32 \%$ & 3.6 & 3.4 & 3.4 & 1.7 & 3 & 3.4 & 3.4 & 8 & \\
\hline & 3.6 & $46 \%$ & 3.4 & 3.1 & 3.1 & 1.6 & 3 & 3.1 & 3.1 & 7 & \\
\hline & 34 & $\$ 1 \%$ & 3.3 & 2.9 & 2.9 & 14 & 3 & 2.9 & 2.9 & 6 & \\
\hline & 3.3 & $36 \%$ & 3.1 & 2.5 & 2.6 & 1.3 & 3 & 2.6 & 2.5 & 5 & \multirow{3}{*}{ Sedang } \\
\hline & 3.1 & $30 \%$ & 2.9 & 2.3 & 2.3 & 1.1 & 2 & 2.3 & 2.3 & 4 & \\
\hline & 3.0 & $23 \%$ & 2.7 & 2.0 & 2.0 & 1.0 & 2 & 2.0 & 2.0 & 3 & \\
\hline & 2.8 & $20 \%$ & 2.5 & 1.7 & 1.7 & 0.7 & 2 & 1.7 & 1.7 & 2 & \multirow{2}{*}{ Buruk } \\
\hline & 2.7 & $15 \%$ & 2.2 & 1.3 & 1.3 & 0.3 & 1 & 1.3 & 1.3 & 1 & \\
\hline & 2.5 & $10 \%$ & 2.0 & 1.0 & 1.0 & 0.0 & 1 & 1.0 & 1.0 & 0 & Sangat Buruk \\
\hline Keterangan KPI & $\begin{array}{l}\text { Higher Is } \\
\text { Better }\end{array}$ & $\begin{array}{c}\text { Figher iz } \\
\text { Better }\end{array}$ & 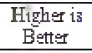 & $\begin{array}{l}\text { Figher iz } \\
\text { Better }\end{array}$ & $\begin{array}{l}\text { Higher iz } \\
\text { Better }\end{array}$ & $\begin{array}{l}\text { Higher is } \\
\text { Better }\end{array}$ & $\begin{array}{c}\text { Highter is } \\
\text { Better }\end{array}$ & $\begin{array}{l}\text { Higher is } \\
\text { Better }\end{array}$ & $\begin{array}{c}\text { Higher is } \\
\text { Better }\end{array}$ & & \\
\hline Score & 6 & 7 & 5 & 6 & 6 & 3 & 6 & 6 & 6 & & \\
\hline Babot & 0.041667 & 0.041667 & 0.041667 & 0.041657 & 0.041667 & 0.041667 & 0.041667 & 0.041667 & 0.041657 & & \\
\hline Milai Kinerja & 0.25 & 0.29 & 0.21 & 0.25 & 0.25 & 0.13 & 0.25 & 0.25 & 0.25 & & \\
\hline SIAIUS KIXERJA & Baik & Baik & Sedane & Baik & Baik & Sedane & Bailik & Baik: & Bailk & & \\
\hline
\end{tabular}

Tabel 5. Contoh Lembar Kerja Pengukuran Kinerja KPI 19 - KPI 24

\begin{tabular}{|c|c|c|c|c|c|c|c|c|}
\hline Indikator Kinerja (KPI) & KPI 19 & KPI 20 & KPI 21 & KPI 22 & KPI 23 & KPI 24 & SCORF & KETERAYGAY \\
\hline Pencapaian & 3.0 & 4.0 & 3.0 & 3.0 & 3.0 & 20.0 & & \\
\hline Target & 4.0 & 4.0 & 4.0 & 4.0 & 4.0 & 30.0 & 10 & Sangat Baik \\
\hline & 3.7 & 3.9 & 3.8 & 3.8 & 3.8 & 27.1 & 9 & \multirow{4}{*}{ Baik } \\
\hline & 3.4 & 3.7 & 3.6 & 3.6 & 3.6 & 24.3 & 8 & \\
\hline & 3.1 & 3.6 & 3.4 & 3.4 & 3.4 & 21.4 & 7 & \\
\hline & 2.9 & 3.4 & 3.3 & 3.3 & 3.3 & 18.6 & 6 & \\
\hline & 2.6 & 3.3 & 3.1 & 3.1 & 3.1 & 15.7 & 5 & \multirow{3}{*}{ Sedang } \\
\hline & 2.3 & 3.1 & 2.9 & 2.9 & 29 & 12.9 & 4 & \\
\hline & 2.0 & 3.0 & 2.7 & 2.3 & 2.7 & 10.0 & 3 & \\
\hline & 1.7 & 2.7 & 2.5 & 2.5 & 2.5 & 8.3 & 2 & \multirow{2}{*}{ Burvk } \\
\hline & 1.3 & 2.3 & 2.2 & 2.2 & 2.2 & 6.7 & 1 & \\
\hline & 1.0 & 20 & 20 & 2.0 & 20 & 50 & 0 & \multirow[t]{6}{*}{ Sangat Buruk } \\
\hline Keterangan KPI & $\begin{array}{c}\text { Higher is } \\
\text { Better }\end{array}$ & $\begin{array}{l}\text { Higher is } \\
\text { Better }\end{array}$ & $\begin{array}{l}\text { Higher is } \\
\text { Better }\end{array}$ & $\begin{array}{c}\text { Higher is } \\
\text { Better }\end{array}$ & $\begin{array}{c}\text { Higher is } \\
\text { Better }\end{array}$ & $\begin{array}{c}\text { Higher is } \\
\text { Better }\end{array}$ & & \\
\hline Score & 6 & 10 & 5 & 5 & 5 & 7 & Yilai Total & \\
\hline Robot & 0.041667 & 0.041667 & 0.041667 & 0.041667 & 0.041606 & 0.041663 & Kinerja & \\
\hline Nilai Kierja & 0.25 & 0.42 & 0.21 & 0.21 & 0.21 & 0.20 & 6 & \\
\hline STATLS KTFRJA & Biaik & $\begin{array}{l}\text { Sangat } \\
\text { Baik }\end{array}$ & Sedang & Sedang & Sedang & Baik & $\begin{array}{l}\text { Karegori } \\
\text { Rerkembang }\end{array}$ & \\
\hline
\end{tabular}

\section{Kesimpulan}

1. Persepektif kriteria yang digunakan untuk pengukuran kinerja ada empat, yaitu: persepektif finansial, pelanggan, proses bisnis internal, belajar dan tumbuh.

2. Tujuan-tujuan strategis yang terbentuk ada 10 tujuan strategis

3. Indikator kinerja (Key Performace Indicator - KPI) yang terbentuk ada $24 \mathrm{KPI}$

4. Terbentuknya lembar kerja pengukuran kinerja dengan metode Omax, sehingga dapat diketahui nilai kinerja tiap indikator kinerja dan total kinerja dalam periode tertentu, sehingga dapat diketahui kategori standarisasi desa wisata (embrio, berkembang dan maju). 


\section{Daftar Pustaka}

Albert H.C. Tsang, 1999, Measuring maintenance performance: a holistic approach, International Journal of Operations \& Production Management, Vol. 19 No. 7, \# MCB University Press, 0144-3577, pp. 691-715.

Charles Parket, 2000, Performance Measurement, Work Study, Volume 49 - Number 2, MCB University Press, ISSN 0043-8022, pp 63 - 66.

Expert Choice Decision Support Software Version 9.0, 1995, 4922 Ellsworth Avenue Pittsburgh, PA 15213 USA.

Hamzah, 2011, Teori Kinerja dan Pengukurannya, Bumi Aksara.

Kaplan, Robert S. Norton, David P, 1996, The Balanced Scorecard - Translating Strategy Into Action, Harvard Business School Press, Boston.

Moeheriono, 2012, Pengukuran Kinerja Berbasis Kompetensi, PT. Rja Grafindo Persada.

Nuryanti, Wiendu, 1993, Concept, Perspective and Challenges, Gajah Mada University Press, Hal 2-3.

Rowena Cullen, August 1999, Does performance measurement improve organisational effectiveness? A postmodern analysis, Performance Measurement and Metrics Vol. 1, No. 1, (C) Aslib, The Association for Information Management.

Say, 2015, Desa Wisata Distandarisasi, Tribun Jogja, 26 Maret 2015, hal 9.

Saaty, Thomas Lorie,1988, The Analytic Hierarchy Process, British Library Catalog.

Simons, Robert, 2000, Performance Measurement and Control System for Implementing Strategy, Prentice Hall.

Suwignjo P, Penilaian Kinerja, Program Pascasarjana, ITS, 2000.

Wibisono, 2013, How to create a World Class Company, Gramedia Pustaka Utama. 
Yasrin Zabidi, Suhardiwarno 